\title{
Variations in grazing behaviour of Salers and Limousin heifers during time spent in the paddock in a rotational system
}

\author{
P D'Hour 1, M Petit 1, JP Garel 2, A Mante ${ }^{2}$ \\ 1 INRA, Laboratoire Adaptation des Herbivores aux Milieux, \\ Theix, 63122 Saint-Genès-Champanelle; \\ 2 Domaine INRA, 15190 Marcenat, France
}

Part of the variations in grass intake between different cattle breeds may result from differences in grazing behaviour (Funston et al, 1991). The daily grazing time and bite rate were studied in Salers and Limousin heifers, the latter being known to have the lowest growth rate in pasture.

Eight heifers of each breed, all 18-month-old, were grazing together on good quality hilly pastures (the main grasses were Agrostis stolonifera and Avena pubescens) in a rotational system. The study site (elevation $1150 \mathrm{~m}$ ) was located in the north of the Massit Central (France). The Salers and Limousin heifers weighed $380 \pm 35 \mathrm{~kg}$ and $372 \pm 32 \mathrm{~kg}$, respectively. They were simultaneously observed for $3 d$, during the first (D1: 19/06), seventh (D7: 25/06) and eleventh (D11: $30 / 06$ ) days of the total time (12 d) spent in one of the paddocks. They entered the paddock at $5 \mathrm{pm}$ the previous evening. Herbage mass decreased from $4.7 t$ (D1) to $2.0 t$ (D11) of dry matter per ha, and average grass height decreased from 39 to $10 \mathrm{~cm}$. The activities of each heifer were noted every $5 \mathrm{~min}$ from dawn to dusk (4 am-11 pm). Individual bite rates were measured 4-6 times a day, non-grazing animals excluded. Each time the number of bites taken in 2 min was recorded, and then divided by the real grazing time.

The daily pattem of grazing was similar in both breeds for all $3 d$, with 4 (D1) then 3 (D7 and D11) grazing periods per day. The Limousin heifers tended to graze for longer than the Salers on D1 (414 vs $377 \mathrm{~min} /{ }^{*} \mathrm{~d}, \mathrm{NS}$ ). However Salers tended to further increase their daily grazing time with the decrease in herbage mass $(+43$ vs +2 min from D1 to D7, NS; +66 vs +27 min from D1 to D11, NS). The Salers heifers' grazing times during D1 and D11 were negatively related $(P<$ $0.05)$. Bite rate was different between breeds $(P<$ $0.01)$ and days $(P<0.001)$ and the variations with day were different for each breed $(P<0.05)$. Bite rate was higher in Salers heifers than in Limousin for D1 (32.3 vs 26.7 bites/min) and D11 (40.2 vs 33.8 bites $/ \mathrm{min}$ ) but not for D7 (38.1 vs $39.4 \mathrm{bites} / \mathrm{min})$. There were no significant relationships between bite rates and grazing times.

Estimates of the total number of bites per day (grazing time $\mathrm{x}$ bite rate) were different between breeds (Salers: 15 230, Limousin: 13275 bites/d; $P<0.05)$ and days $(P<0.001)$, but variations with day were not statistically different between breeds $(P=0.1)$. If the mean bite size was the same for each breed, the difference in the daily number of bites would lead to a $14 \%$ difference in grass intake, which is slightly higher than the differences observed in dry matter intake of harvested forages (Agabriel et al, 1987).

The Salers heifers seem to be less sensitive than Limousin heifers to the decrease in available herbage during the time spent in a paddock, by maintaining a higher bite rate.

Agabriel J, D'Hour P, Petit M (1987) Reprod Nutr Dev27 (1b), 211-212

Funston RN, Kress DD, Havstad KM, Doornbos DE (1991) J Anim Sci 69, 1435-1442 